\title{
Effects of Clavien-Dindo classification on long-term survival of patients with advanced gastric cancer after radical resection:A propensity score-matched study
}

\section{Wenwu Yan}

Yijishan Hospital of Wannan Medical College

Jun Du

Yijishan Hospital of Wannan Medical College

Qingyi Li

Yijishan Hospital of Wannan Medical College

Changsheng Yao

Yijishan Hospital of Wannan Medical College

Mengxiang Zhu

Yijishan Hospital of Wannan Medical College

Jinguo Wang ( $\square$ shwangjg@sina.com )

Yijishan Hospital of Wannan Medical College https://orcid.org/0000-0002-6100-6022

\section{Research}

Keywords: Advanced gastric cancer, Postoperative complication, Clavien-Dindo classification, Long-term survival

Posted Date: January 14th, 2021

DOl: https://doi.org/10.21203/rs.3.rs-139111/v1

License: (c) (i) This work is licensed under a Creative Commons Attribution 4.0 International License. Read Full License 


\section{Abstract}

Background The impact of postoperative complications (POCs) classified by the Clavien-Dindo (C-D) system on long-term survival after radical resection in patients with advanced gastric cancer (AGC) is not yet clear.

Methods This study analyzed 531 patients with AGC who underwent radical resection in an institution between January 2015 and December 2017. Patients were divided into two groups according to the occurrence of POCs and recorded according to C-D classifications. The long-term survival outcomes of the entire cohort after propensity score matching (PSM) were compared.

Results After PSM, there was no significant difference in baseline data between the complications (C) group ( $n=92)$ and the non-complications (NC) group $(n=92)$. Survival analysis showed that the 5-year

overall survival (OS) and relapse-free survival (RFS) were lower in the C group (48.9\% vs. $62.0 \%, p=0.040$; $38.5 \%$ vs. $54.9 \%, p=0.005$; respectively). Subgroup analysis showed that severe complications (C-D grade $>$ II) were associated with a decrease in 5-year OS and RFS compared with the matched NC group $(40.0 \%$ vs. $62.0 \%, p=0.008 ; 29.4 \%$ vs. $54.9 \%, p=0.001$; respectively). Multivariate analysis confirmed adjuvant chemotherapy, tumor size, and complications were independent risk factors for poor survival outcomes. Further multivariate analysis showed that older age, combined excision, and comorbidities were independent risk factors for POCs.

Conclusions Severe complications reduced the survival outcome of patients.Older age, combined excision, and comorbidities were independent risk factors for POCs. More attention should be paid to perioperative management of patients with high risk factors for complications.

\section{Introduction}

Gastric cancer is a global disease, the fourth leading cause of cancer-related deaths worldwide[1], and the second leading cause of cancer-related deaths in China[2]. Radical resection of gastric cancer lesions combined with adequate lymph node dissection is key to treatment of gastric cancer. However, radical resection of gastric cancer is still technically difficult $邓$ the incidence of postoperative complications (POCs) of gastric cancer was reported to be $12.9 \otimes 24.4 \%$ [3-5].The most common POCs are anastomotic problems, obstruction, infectious complications such as pneumonia, abdominal abscess, urinary tract infection, incision infection, etc.

POCs were defined as any deviation from normal postoperative course[6], which were always associated with longer hospital stays, increased economic costs, and increased mortality [7, 8].In recent years, studies have reported that POCs are a negative predictor of long-term survival outcomes[9-11].Some researchers have suggested that the immune response of POCs may provide a suitable microenvironment for tumor cells remaining after surgery, thus promoting tumor recurrence and deterioration of survival outcomes[12, 13]. 
In this study, propensity score matching (PSM) was used to assess the impact of POCs on patient longterm survival outcomes to reduce potential confounders.C-D grade above level I was considered to have complications, otherwise it was considered to have no complications. Complications above grade II were considered serious. Multiple complications occurred in one patient, with only the most severe recorded. This study will provide a strong basis for us to reduce the incidence of POCS and better preoperative communication with patients and their families.

\section{Materials And Methods}

\section{Patients}

Patients were selected from our prospectively maintained gastric cancer database from January 2015 to December 2017. Inclusion criteria for the study were as follows: (1) adenocarcinoma confirmed by gastroscopy and pathological biopsy; (2) invasion depth greater than pT1; (3) no distant metastasis; (4) radical resection (R0) was performed; (5) other malignant tumors were not present; (6) emergency surgery was not performed; and (7) preoperative chemotherapy or radiotherapy was not performed. Pathological staging was graded according to the $8^{\text {th }}$ Union for International Cancer Control (UICC)/American Joint Committee on Cancer (AJCC) staging system of gastric cancer [14]. PSM with a 0.02 caliper width was used to match the two groups on a 1:1 basis. The study was approved by our institute's ethics review committee.

\section{Postoperative evaluation and follow-up}

POCs were classified according to the Clavien-Dindo (C-D) classification system[6, 15].Patients were followed up every 3 months for the first 2 years, then every 6 months for 2 to 5 years, and then once a year. OS was defined as the time from surgery to death or the last follow-up. RFS was defined as the time of surgical to recurrence, death, or the last follow-up. The final follow-up date was October 2020.

\section{Statistical analysis}

To reduce the impact of clinicopathological characteristics on survival outcomes, 1:1 PSM was performed using a logistic regression model and the following covariates: sex, age, body mass index (BMI), preoperative albumin, surgical method, resection range, history of upper abdominal surgery, combined resection, tumor size, comorbidities, pT stage, pN stage, pTNM stage, and adjuvant chemotherapy. The chi-square or Fisher's exact test was used to compare categorical variables between the two groups. The survival rate was compared by the Kaplan-Meier method and long-rank test. Multivariate analysis was performed using the Cox proportional hazard model to determine independent risk factors for OS and RFS reduction. Multivariate analysis was performed using a binary logistic regression model to identify independent risk factors for POCs. P-values less than 0.05 were considered statistically significant. SPSS version 25.0 (SPSS Inc., Chicago, IL, USA) was used for statistical analysis and PSM. 


\section{Results}

\section{Clinicopathological characteristics}

Table 1 shows the patient characteristics of the entire cohort $(n=531)$ and the PSM cohort $(n=$ 184).There were differences in age, preoperative albumin, combined resection, comorbidities, and pT staging between the $C$ and NC groups $(P<0.05)$. After $P S M$, patient characteristics were balanced in terms of age, sex, BMI, preoperative albumin, comorbidities, surgical method, resection range, combined resection, tumor size, pT stage, pN stage, pTNM stage, and postoperative chemotherapy.

\section{Postoperative complications}

Table 2 shows the details of POCs classified by C-D classification. The overall incidence of POCs was $17.7 \%$ (94/531) among the 531 patients in the entire cohort. The incidence of serious complications was $6.6 \%(35 / 531)$.

\section{Survival outcomes}

The median follow-up time was 47 months. POCs were associated with decreased 5 -year OS (48.9\% vs. $62.0 \%, p=0.040)$ (Fig. $1 \mathrm{~A})$ and RFS (38.5\% vs. $54.9 \%, p=0.005)($ Fig. $1 \mathrm{~B})$, indicating that the survival status of the $\mathrm{C}$ group was better than that of the $\mathrm{NC}$ group, this difference was statistically significant.

To further assess the impact of different C-D levels, we analyzed the survival outcomes of grade II POCs and matched NC groups. Grade II POCs had a tendency to decrease 5-year OS (54.4\% vs. $62.0 \%, \mathrm{p}=$ 0.262 ) (Fig. $2 \mathrm{~A}$ ) and RFS (43.9\% vs. $54.9 \%, p=0.074)$ (Fig. 2B), although the difference was not statistically significant. Another subgroup analysis showed that severe complications (C-D grade $>$ II) reduced OS (40.0\% vs. $62.0 \%, p=0.008)$ (Fig. $3 A$ )and RFS (29.4\% vs. $54.9 \%, p=0.001)$ (Fig. $3 B$ ) compared with the matched NC group; this difference was statistically significant.

We also assessed the differences between grade C-D II and severe complications. The results showed that severe complications reduced OS $(37.2 \%$ vs. $59.2 \%, p=0.023)$ (Fig. $4 \mathrm{~A})$ in a statistically significant manner and tended to reduce RFS $(28.6 \%$ vs. $46.9 \%, p=0.054)($ Fig. $4 \mathrm{~B})$, but this difference was not statistically significant.

\section{Risk factors for POCs}

Multivariate analysis showed that age over 50 , combined resection, and comorbidities were independent predictors of POCs (Table 3 ).

\section{Risk factors associated with decreased OS and RFS}

Multivariate analysis showed that POCs, stage PTNM III, tumor diameter $>5 \mathrm{~cm}$, and absence of adjuvant chemotherapy were independent predictors of OS and RFS reduction (Table 4). 


\section{Discussion}

This study investigated the relationship between POCs and OS and RFS after radical gastrectomy for advanced gastric cancer. POCs can prolong hospital stay, and increase cost and postoperative mortality. Studies have shown that POCs can reduce the long-term survival outcome of colorectal cancer[16-18]; the same trend has also been observed in gastric cancer[9, 19,20].

In this study, we use C-D classification to classify POCs; this system has been regarded as a classical classification method and has been used to classify a variety of POCs $[6,15]$. It has also been used to classify POCs of gastric cancer $[21,22]$. The cohort was divided into two groups according to the presence of complications. Because the baseline characteristics of patients between the two groups were not comparable, we used PSM to reduce potential confounding factors and selection bias.

The present study showed that POCs were related to poor long-term survival outcomes. To evaluate the relationship between complication grade and survival outcome, we further analyzed the impact of C-D grade complications and severe complications on survival outcome. We found that grade complications had a negative effect on 5-year OS and RFS, but the results were not statistically significant, in contrast with a previous study[23]. Another subgroup analysis showed that severe complications reduced OS and RFS in patients with severe complications; this difference was statistically significant. Further subgroup analysis showed that severe complications reduced RFS in patients with severe complications compared with grade II complications. At the same time, there was a trend of negative impact on OS, but the results did not reach statistical significance $(P>0.05)$.

Because of the negative impact of POCs on survival outcome, it is necessary to understand the risk factors and take intervening measures. We carried out single- and multi-factor analyses in the whole cohort of in this study. Multivariate analysis showed that age over 50 , combined resection, and comorbid diseases were independent risk factors for POCs. Many studies have shown that there is a relationship between advanced age and the occurrence of POCs[24, 25], which is consistent with our research. Old age will lead to a decrease in the physiological function of various organs, deterioration of nutritional status, and a decrease of anesthetic tolerance, which may be related to the increase of POCs. Therefore, in the perioperative management of patients, more attention should be paid to elderly patients.

A number of studies have shown that combined resection is associated with an increase in POCs[24, 26]; our study came to the same conclusion. Combined organ resection can prolong the operation time and increase the scope of surgical injury, which may increase POCs compared with gastrectomy alone. Previous studies have shown that gastrectomy combined with splenectomy or pancreatectomy increases the incidence of POCs and does not improve survival[27-29]. In addition, studies have shown that combined resection may negatively affect the recurrence-free survival of patients[30]. Therefore, more caution should be taken in deciding whether to perform multiple organ resection.

In terms of comorbidities, many studies have shown that comorbidities increase POCs [31-33], which is consistent with our results. This may be related to the fact that co-disease can reduce the patient's 
respiratory and cardiac reserves. In addition, studies have shown that diabetes is associated with infectious complications [34,35]. Therefore, appropriate perioperative management of patients with comorbid diseases is necessary.

A large number of studies have indicated that adjuvant chemotherapy can significantly improve the survival outcome of patients with advanced gastric cancer [36-38]. In our study, the chemotherapy data of the two groups were similar after PSM. As a result, the potential effect of adjuvant chemotherapy on survival outcome was eliminated to the greatest extent.

Thus far, the mechanism by which complications lead to poor survival outcomes is unclear. The generally accepted explanation is that the inflammatory microenvironment can promote tumor development, while complications can lead to a severe inflammatory response, which suppresses the patient's immune system and promotes tumor recurrence and metastasis[12, 13].

There were some limitations of this study. First, this study was a single-center retrospective study. Second, the operation was performed by multiple groups of physicians, and the influence of surgical experience on the outcome of the operation could not be ruled out[31]. Finally, PSM could not rule out all deviations; there may be other variables that affect surgical outcomes and survival outcomes that were not included in the study.

\section{Conclusions}

In conclusion, POCs had a negative impact on the long-term survival of patients with advanced gastric cancer, and severe complications (C-D grade $>$ II) significantly reduced survival. Therefore, more attention should be paid to the perioperative management of patients older than 50 years, with combined resection and comorbid diseases.

\section{Abbreviations}

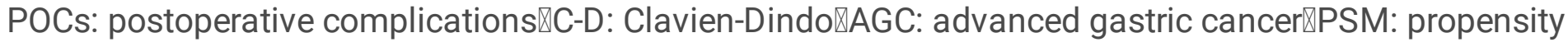

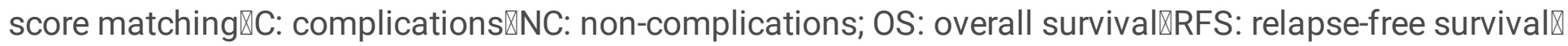
UICC: Union for International Cancer Control『AJCC: American Joint Committee on Cancer囚BMI: body

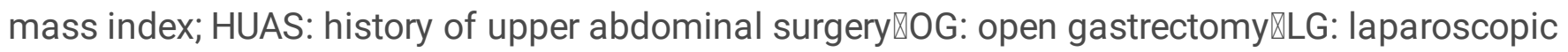

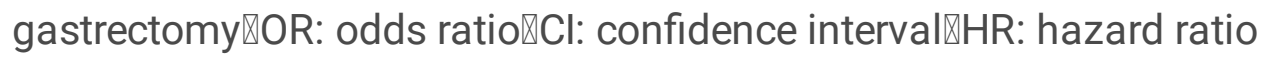

\section{Declarations}

\section{Authors' contributions}

Y-WW designed this research and reviewed and edited the manuscript; D J prepared the original draft and completed the manuscript; L-QY, Y-CS, and Z-MX were in charge of data collection.W-JG contributed to 
the conception, design, and data nterpretation, as well as revised the manuscript for important intellectual content. All authors read and approved the final manuscript.

\section{Funding}

This study did not receive any type of funding.

\section{Availability of data and materials}

The datasets used and/or analysed during the current study are available from the corresponding author on reasonable request.

\section{Ethics approval and consent to participate}

All procedures followed were in accordance with the ethical standards of the responsible committee on human experimentation (institutional and national) and with the Helsinki Declaration of 1964 and later versions. The retrospective study was approved by the Ethics Committee of Yijishan Hospital. The informed consent requirement was waved.

\section{Conflict of interest statement}

All authors declared that they have no conflicts of interest.

\section{Consent for publication}

Not applicable.

\section{References}

1. Bray F, Ferlay J, Soerjomataram I, Siegel RL, Torre LA, Jemal A: Global cancer statistics 2018 : GLOBOCAN estimates of incidence and mortality worldwide for 36 cancers in 185 countries. $C A$ Cancer J Clin 2018, 68:394-424.

2. Chen $W$, Zheng R, Baade PD, Zhang S, Zeng H, Bray F, Jemal A, Yu XQ, He J: Cancer statistics in China, 2015. CA Cancer J Clin 2016, 66:115-132.

3. Hu Y, Huang C, Sun Y, Su X, Cao H, Hu J, Xue Y, Suo J, Tao K, He X, et al: Morbidity and Mortality of Laparoscopic Versus Open D2 Distal Gastrectomy for Advanced Gastric Cancer: A Randomized Controlled Trial. J Clin Oncol 2016, 34:1350-1357.

4. Liu F, Huang C, Xu Z, Su X, Zhao G, Ye J, Du X, Huang H, Hu J, Li G, et al: Morbidity and Mortality of Laparoscopic vs Open Total Gastrectomy for Clinical Stage I Gastric Cancer: The CLASSO2 Multicenter Randomized Clinical Trial. Jama Oncol 2020, 6:1590-1597.

5. Oh SY, Kwon S, Lee KG, Suh YS, Choe HN, Kong SH, Lee HJ, Kim WH, Yang HK: Outcomes of minimally invasive surgery for early gastric cancer are comparable with those for open surgery: analysis of 1,013 minimally invasive surgeries at a single institution. Surg Endosc 2014, 28:789-795. 
6. Dindo D, Demartines N, Clavien PA: Classification of surgical complications: a new proposal with evaluation in a cohort of 6336 patients and results of a survey. Ann Surg 2004, 240:205-213.

7. Sauvanet A, Mariette C, Thomas P, Lozac'H P, Segol P, Tiret E, Delpero JR, Collet D, Leborgne J, Pradere $\mathrm{B}$, et al: Mortality and morbidity after resection for adenocarcinoma of the gastroesophageal junction: predictive factors. J Am Coll Surg 2005, 201:253-262.

8. Jin LX, Sanford DE, Squires MR, Moses LE, Yan Y, Poultsides GA, Votanopoulos KI, Weber SM, Bloomston M, Pawlik TM, et al: Interaction of Postoperative Morbidity and Receipt of Adjuvant Therapy on Long-Term Survival After Resection for Gastric Adenocarcinoma: Results From the U.S. Gastric Cancer Collaborative. Ann Surg Oncol 2016, 23:2398-2408.

9. Kubota T, Hiki N, Sano T, Nomura S, Nunobe S, Kumagai K, Aikou S, Watanabe R, Kosuga T, Yamaguchi T: Prognostic significance of complications after curative surgery for gastric cancer. Ann Surg Oncol 2014, 21:891-898.

10. Fujiya K, Tokunaga M, Mori K, Makuuchi R, Tanizawa Y, Bando E, Kawamura T, Terashima M: LongTerm Survival in Patients with Postoperative Intra-Abdominal Infectious Complications After Curative Gastrectomy for Gastric Cancer: A Propensity Score Matching Analysis. Ann Surg Oncol 2016, 23:809-816.

11. Wang SL, Ma LL, Chen XY, Zhou DL, Li B, Huang DD, Yu Z, Shen X, Zhuang CL: Impact of visceral fat on surgical complications and long-term survival of patients with gastric cancer after radical gastrectomy. Eur J Clin Nutr 2018, 72:436-445.

12. Mantovani A, Allavena P, Sica A, Balkwill F: Cancer-related inflammation. Nature 2008, 454:436-444.

13. Goldfarb Y, Sorski L, Benish M, Levi B, Melamed R, Ben-Eliyahu S: Improving postoperative immune status and resistance to cancer metastasis: a combined perioperative approach of immunostimulation and prevention of excessive surgical stress responses. Ann Surg 2011, 253:798810.

14. Sano T, Coit DG, Kim HH, Roviello F, Kassab P, Wittekind C, Yamamoto Y, Ohashi Y: Proposal of a new stage grouping of gastric cancer for TNM classification: International Gastric Cancer Association staging project. Gastric Cancer 2017, 20:217-225.

15. Clavien PA, Barkun J, de Oliveira ML, Vauthey JN, Dindo D, Schulick RD, de Santibanes E, Pekolj J, Slankamenac K, Bassi C, et al: The Clavien-Dindo classification of surgical complications: five-year experience. Ann Surg 2009, 250:187-196.

16. Wang D, Zhang J, Bai Z, Yang Y, Wang T, Jin L, Wang J, Wu G, Kou T, Zhang Z: Associations of Postoperative Complications Assessed by Clavien-Dindo Classification and Comprehensive Complication Index with Long-Term Overall Survival in Elderly Patients after Radical CRC Resection. Clin Interv Aging 2020, 15:1939-1949.

17. Cienfuegos JA, Baixauli J, Beorlegui C, Ortega PM, Granero L, Zozaya G, Hernandez LJ: The impact of major postoperative complications on long-term outcomes following curative resection of colon cancer. Int J Surg 2018, 52:303-308. 
18. Law WL, Choi HK, Lee YM, Ho JW: The impact of postoperative complications on long-term outcomes following curative resection for colorectal cancer. Ann Surg Oncol 2007, 14:2559-2566.

19. Tokunaga M, Kurokawa Y, Machida R, Sato Y, Takiguchi S, Doki Y, Yabusaki H, Watanabe M, Hato S, Nakamori M, et al: Impact of postoperative complications on survival outcomes in patients with gastric cancer: exploratory analysis of a randomized controlled JCOG1001 trial. Gastric Cancer

20. Yuan P, Wu Z, Li Z, Bu Z, Wu A, Wu X, Zhang L, Shi J, Ji J: Impact of postoperative major complications on long-term survival after radical resection of gastric cancer. Bmc Cancer 2019, 19:833.

21. Zhou J, Yu P, Shi Y, Tang B, Hao Y, Zhao Y, Qian F: Evaluation of Clavien-Dindo classification in patients undergoing total gastrectomy for gastric cancer. Med Oncol 2015, 32:120.

22. Li Z, Bai B, Ji G, Li J, Zhao Q: Relationship between Clavien-Dindo classification and long-term survival outcomes after curative resection for gastric cancer: A propensity score-matched analysis. Int J Surg 2018, 60:67-73.

23. Duraes LC, Stocchi L, Steele SR, Kalady MF, Church JM, Gorgun E, Liska D, Kessler H, Lavryk OA, Delaney CP: The Relationship Between Clavien-Dindo Morbidity Classification and Oncologic Outcomes After Colorectal Cancer Resection. Ann Surg Oncol 2018, 25:188-196.

24. Park DJ, Lee HJ, Kim HH, Yang HK, Lee KU, Choe KJ: Predictors of operative morbidity and mortality in gastric cancer surgery. Br J Surg 2005, 92:1099-1102.

25. Yu J, Hu J, Huang C, Ying M, Peng X, Wei H, Jiang Z, Du X, Liu Z, Liu H, Li G: The impact of age and comorbidity on postoperative complications in patients with advanced gastric cancer after laparoscopic D2 gastrectomy: results from the Chinese laparoscropic gastrointestinal surgery study (CLASS) group. Eur J Surg Oncol 2013, 39:1144-1149.

26. McCulloch P, Ward J, Tekkis PP: Mortality and morbidity in gastro-oesophageal cancer surgery: initial results of ASCOT multicentre prospective cohort study. BMJ 2003, 327:1192-1197.

27. Kasakura Y, Fujii M, Mochizuki F, Kochi M, Kaiga T: Is there a benefit of pancreaticosplenectomy with gastrectomy for advanced gastric cancer? Am J Surg 2000, 179:237-242.

28. Marano L, Rondelli F, Bartoli A, Testini M, Castagnoli G, Ceccarelli G: Oncologic Effectiveness and Safety of Splenectomy in Total Gastrectomy for Proximal Gastric Carcinoma: Meta-analysis of Randomized Controlled Trials. Anticancer Res 2018, 38:3609-3617.

29. Csendes A, Burdiles P, Rojas J, Braghetto I, Diaz JC, Maluenda F: A prospective randomized study comparing D2 total gastrectomy versus D2 total gastrectomy plus splenectomy in 187 patients with gastric carcinoma. Surgery 2002, 131:401-407.

30. Muneoka Y, Akazawa K, Ishikawa T, Ichikawa H, Nashimoto A, Yabusaki H, Tanaka N, Kosugi SI, Wakai T: Nomogram for 5-year relapse-free survival of a patient with advanced gastric cancer after surgery. Int J Surg 2016, 35:153-159.

31. Kim MC, Kim W, Kim HH, Ryu SW, Ryu SY, Song KY, Lee HJ, Cho GS, Han SU, Hyung WJ: Risk factors associated with complication following laparoscopy-assisted gastrectomy for gastric cancer: a largescale korean multicenter study. Ann Surg Oncol 2008, 15:2692-2700. 
32. Kim W, Song KY, Lee HJ, Han SU, Hyung WJ, Cho GS: The impact of comorbidity on surgical outcomes in laparoscopy-assisted distal gastrectomy: a retrospective analysis of multicenter results. Ann Surg 2008, 248:793-799.

33. Palmer P, Egger M, Philips P, McMasters KM, Scoggins CR, Martin R: Predictive preoperative and intraoperative factors of anastomotic leak in gastrectomy patients. Am J Surg 2020, 220:376-380.

34. Kellermeyer $B$, Lange L, Wazen JJ: Post-operative infection rates in linear vs. punch technique for bone anchored hearing systems. Am J Otolaryngo/ 2020, 41:102745.

35. Blood AG, Sandoval MF, Burger E, Halverson-Carpenter K: Risk and Protective Factors Associated with Surgical Infections among Spine Patients. Surg Infect (Larchmt) 2017, 18:234-249.

36. Smyth EC, Verheij M, Allum W, Cunningham D, Cervantes A, Arnold D: Gastric cancer: ESMO Clinical Practice Guidelines for diagnosis, treatment and follow-up. Ann Oncol 2016, 27:v38-v49.

37. Han J, Nie Z, Li P, Shi H, Wang S, Li Q, Zhang R, Qiao Y, Huang K, Fu Z: Comparison of Treatment Modalities for Locally Advanced Gastric Cancer: A Propensity Score Matching Analysis. J Cancer 2020, 11:4421-4430.

38. Smyth EC, Nilsson M, Grabsch HI, van Grieken NC, Lordick F: Gastric cancer. Lancet 2020, 396:635648.

\section{Tables}

Table 1 Characteristics of patients 


\begin{tabular}{lll}
\hline Variables & Enter chort & PSM chort
\end{tabular}

\begin{tabular}{llllll}
\hline $\mathrm{C}$ group $\llbracket \mathrm{n}=94 \square$ & $\mathrm{NC}$ group $\llbracket \mathrm{n}=437 \square$ & $\mathrm{P}$ & $\mathrm{C}$ group $\llbracket \mathrm{n}=92 \square$ & $\mathrm{NC}$ group $\llbracket \mathrm{n}=92 \square$ & $\mathrm{P}$
\end{tabular}

\begin{tabular}{|c|c|c|c|c|c|}
\hline Age】years) & & & & & 1.000 \\
\hline$\leq 50$ & 2 & 51 & 2 & 2 & \\
\hline 050 & 92 & 386 & 90 & 90 & \\
\hline
\end{tabular}

Sex

$\begin{array}{cc}\text { Male } & 69 \\ \text { Female } & 25\end{array}$

0.566

333

69

67

0.737

104

23

25

BMI $\left(\mathrm{kg} / \mathrm{m}^{2}\right)$

$\mathbf{2 5}$

0.658

0.835

$\square 25$

15

375

78

79

$14 \quad 13$

Preoperative albumin (g/L)
0.008

0.412

$$
\leq 30
$$

$\square 30$

14

80

Surgical method

$$
\text { LG }
$$

61

Resection extent

$$
\begin{gathered}
\text { Total } \\
\text { Subtotal }
\end{gathered}
$$

Combined resection

$$
\text { Yes }
$$$$
\text { No }
$$

Combidities

$$
\text { Yes }
$$$$
\text { No }
$$

HUAS

$\begin{array}{cc}\text { Yes } & 8 \\ \text { NO } & 86\end{array}$

Tumou size $(\mathrm{cm})$

$\begin{array}{ll}\leq 5 & 70 \\ \square 5 & 24\end{array}$

pTNM

$\begin{array}{ll}\text { I } & 6 \\ \text { II } & 23 \\ \text { III } & 65\end{array}$

pT
81

38

56

8

86

70

24

6

23

65

11
29

408

0.332

177

260

199

238

30

407

0.002

109

328

21

416

301

136

40

130

267

91

0.641

0.025

0.152

0.284

0.135

0.008
0.376

41

45

51

47

11

81

0.880

37

36

55

56

0.268

$\begin{array}{ll}7 & 4\end{array}$

85

88

0.404

$70 \quad 65$

$22 \quad 27$

0.770

$\begin{array}{cc}6 & 6 \\ 22 & 24 \\ 64 & 62\end{array}$

0.876 


$\begin{array}{lllll}3 & 22 & 125 & 22 & 26 \\ 4 & 61 & 221 & 59 & 57\end{array}$

$\mathrm{pN}$

0.398

0.950

$\begin{array}{lcccc}0 & 24 & 100 & 23 & 26 \\ 1 & 16 & 86 & 16 & 15 \\ 2 & 28 & 98 & 27 & 22 \\ 3 & 26 & 153 & 26 & 29\end{array}$

Adjuvant chemotherapy

0.886

0.555

$\begin{array}{lll}\text { Yes } & 44 & 20 \\ \text { No } & 50 & 23\end{array}$

$201 \quad 43$

49

47

45

HUAS history of upper abdominal surgery, OG open gastrectomy, LG laparoscopic gastrectomy

Table 2 Postoperative complications

\begin{tabular}{|c|c|c|c|c|c|c|}
\hline \multirow[t]{2}{*}{ Variables } & \multicolumn{5}{|c|}{ C-D classfication } & \multirow[t]{2}{*}{ Total } \\
\hline & Grade [ & Grade $\square \mathrm{a}$ & Grade $\square \mathrm{b}$ & Grade $\square a$ & Grade $0 \mathrm{~b}$ & \\
\hline Wound problem & 7 & 4 & 2 & 0 & 0 & 13 \\
\hline Pulmonary & 8 & 6 & 0 & 1 & 1 & 16 \\
\hline Thromboembolus & 1 & 0 & 0 & 0 & 0 & 1 \\
\hline Gastroparesis & 6 & 1 & 0 & 0 & 0 & 7 \\
\hline Duodenal stump leakage & 5 & 0 & 3 & 0 & 1 & 9 \\
\hline Anastomotic fistula & 3 & 2 & 1 & 1 & 0 & 7 \\
\hline Anastomotic bleeding & 2 & 0 & 1 & 0 & 0 & 3 \\
\hline Anastomotic stricture & 2 & 2 & 0 & 0 & 0 & 4 \\
\hline Cardiac & 3 & 0 & 0 & 2 & 0 & 5 \\
\hline Hepatic & 3 & 0 & 0 & 0 & 0 & 3 \\
\hline Pancreatic fistula & 2 & 1 & 0 & 0 & 0 & 3 \\
\hline Intestinal obstruction & 5 & 0 & 1 & 0 & 0 & 6 \\
\hline Intra-abdominal bleeding & 2 & 0 & 4 & 0 & 0 & 6 \\
\hline Intraperitoneal abscess & 6 & 3 & 0 & 1 & 0 & 10 \\
\hline Splenic infarction & 2 & 0 & 0 & 0 & 0 & 2 \\
\hline Total & 57 & 19 & 12 & 5 & 2 & 94 \\
\hline
\end{tabular}

Table 3 Multivariate analysis of risk factors for POCs 


\begin{tabular}{|c|c|c|c|c|c|}
\hline \multirow[t]{2}{*}{ Variables } & \multicolumn{2}{|c|}{ No. of patient } & \multicolumn{2}{|c|}{ Multivariate } & \multirow[t]{2}{*}{$\bar{P}$} \\
\hline & group & group & $\overline{\mathrm{OR}}$ & $95 \% \mathrm{CI}$ & \\
\hline Age(yaers) & & & & & 0.025 \\
\hline$\leq 50$ & 2 & 51 & 1 & & \\
\hline$\square 50$ & 92 & 386 & 5.192 & $1.226-21.993$ & \\
\hline Preoperative albumin(g/L) & & & & & 0.089 \\
\hline$\square 30$ & 80 & 408 & 1 & & \\
\hline$\leq 30$ & 14 & 29 & 1.850 & $0.911-3.759$ & \\
\hline Combined resection & & & & & 0.038 \\
\hline Yes & 41 & 199 & 1 & & \\
\hline No & 53 & 238 & 2.135 & $1.045-4.364$ & \\
\hline Combidities & & & & & 0.048 \\
\hline Yes & 38 & 109 & 1 & & \\
\hline No & 56 & 328 & 1.632 & $1.004-2.652$ & \\
\hline pT & & & & & 0.054 \\
\hline 2 & 11 & 91 & 1 & & \\
\hline 3 & 22 & 125 & 1.476 & $0.673-3.237$ & \\
\hline 4 & 61 & 221 & 2.204 & $1.095-4.438$ & \\
\hline
\end{tabular}

OR odds ratio , CI confidence interval

Table 4. Analysis of prognostic factors associated with decreased survival outcomes 


\begin{tabular}{llcllll}
\hline Variables & \multicolumn{3}{c}{ Univariate } & \multicolumn{3}{c}{ Multivariate } \\
\cline { 2 - 7 } & HR & $95 \%$ CI & P & HR & $95 \%$ CI & P
\end{tabular}

\section{Relapse-free survival}

Adjuvant chemotherapy

$\begin{array}{lcccccc}\text { Yes } & 1 & & 1 & & \\ \text { No } & 0.622 & 0.415-0.932 & 0.021 & 0.667 & 0.440-1.012 & 0.057\end{array}$

Tumor size $(\mathrm{cm})$

\begin{tabular}{|c|c|c|c|c|c|c|}
\hline$\leq 5$ & 1 & & & 1 & & \\
\hline$\square 5$ & 1.758 & $1.144-2.701$ & 0.010 & 1.408 & $0.958-2.287$ & 0.077 \\
\hline & & & 0.000 & & & 0.000 \\
\hline
\end{tabular}

pTNM

1

1

$\begin{array}{lllllll}1.321 & 0.289-6.030 & 0.719 & 1.254 & 0.274-5.745 & 0.771\end{array}$

$\begin{array}{lllllll}\text { [ } & 6.022 & 1.481-24.489 & 0.012 & 5.379 & 1.313-22.037 & 0.019\end{array}$

C-D grade

No

1

0.007

0.008

पa--[b

$1.517 \quad 0.955-2.410$

$0.078 \quad 1.798$

$1.124-2.877$

0.014

$2.216 \quad 1.337-3.674$

$0.002 \quad 2.031$

1.220-3.381

0.006

\section{Overall survival}

Adjuvant chemotherapy

$\begin{array}{ccccccc}\text { Yes } & 1 & & 1 & & \\ \text { No } & 0.501 & 0.320-0.784 & 0.002 & 0.507 & 0.320-0.802 & 0.004\end{array}$

Tumor size (cm)

\begin{tabular}{|c|c|c|c|c|c|c|}
\hline$\leq 5$ & 1 & & & 1 & & \\
\hline 45 & 2.036 & $1.290-3.213$ & 0.002 & 1.725 & $1.085-2.741$ & 0.021 \\
\hline \multirow[t]{4}{*}{ pTNM } & & & 0.000 & & & 0.001 \\
\hline & 1 & & & 1 & & \\
\hline & 1.166 & $0.252-5.398$ & 0.844 & 1.097 & $0.236-5.107$ & 0.906 \\
\hline & 4.522 & $1.109-18.444$ & 0.035 & 3.892 & $0.944-16.050$ & 0.060 \\
\hline C-D grade & & & 0.041 & & & 0.041 \\
\hline 0 & 1 & & & 1 & & \\
\hline 口 & 1.337 & $0.085-2.222$ & 0.262 & 1.641 & $0.977-2.754$ & 0.061 \\
\hline$\square \mathrm{a}-\square \mathrm{b}$ & 2.009 & 1.169-3.453 & 0.012 & 1.886 & $1.094-3.254$ & 0.023 \\
\hline
\end{tabular}

HR hazard ratio

Figures 
$1 \mathrm{~A}$

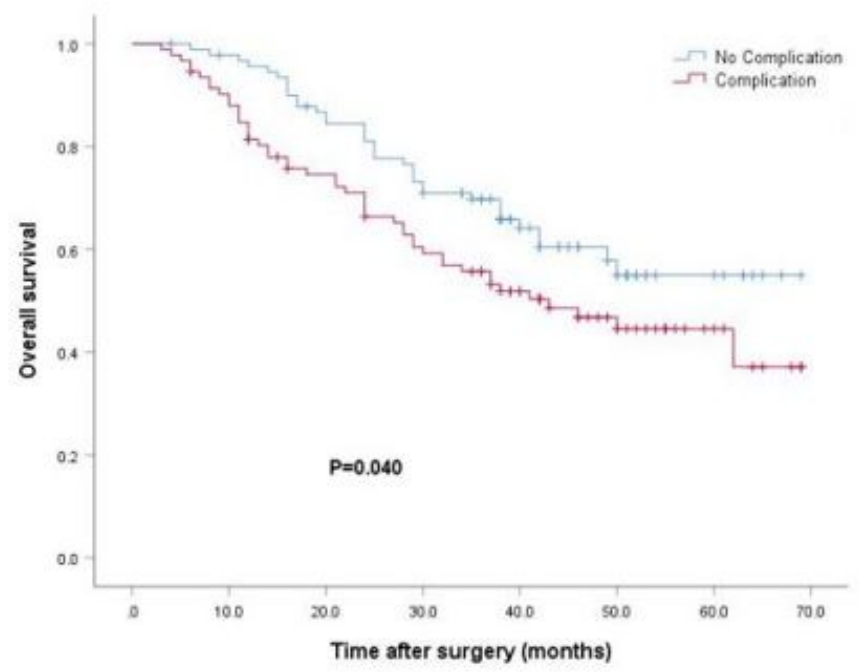

1B

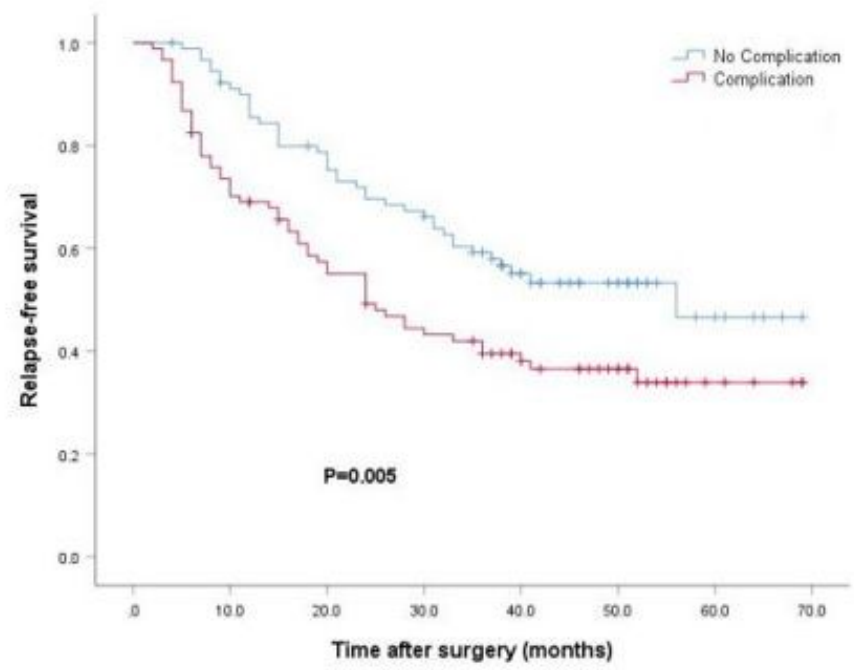

\section{Figure 1}

Comparison of survival outcomes between the $\mathrm{C}$ group and $\mathrm{NC}$ group of all patients in the propensity score-matched cohort(A).

$2 \mathrm{~A}$

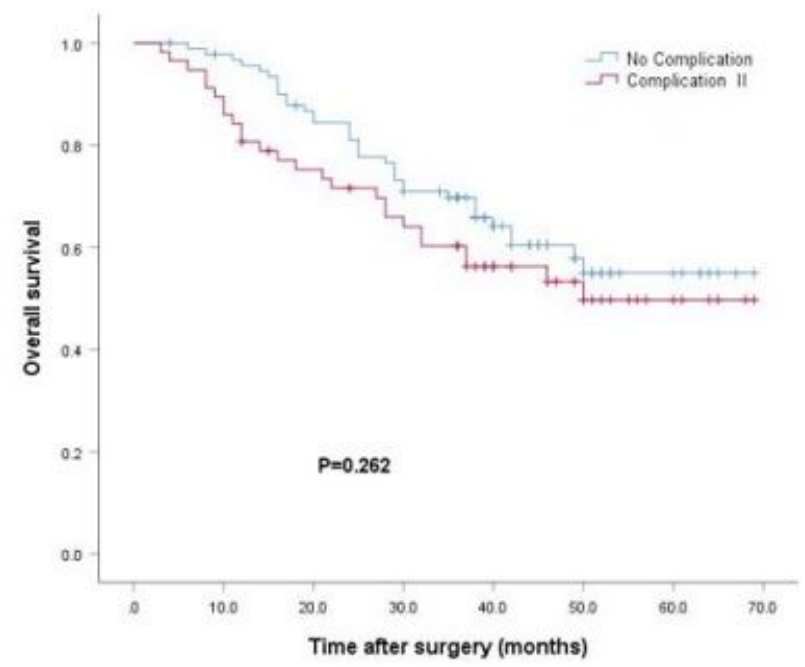

$2 B$

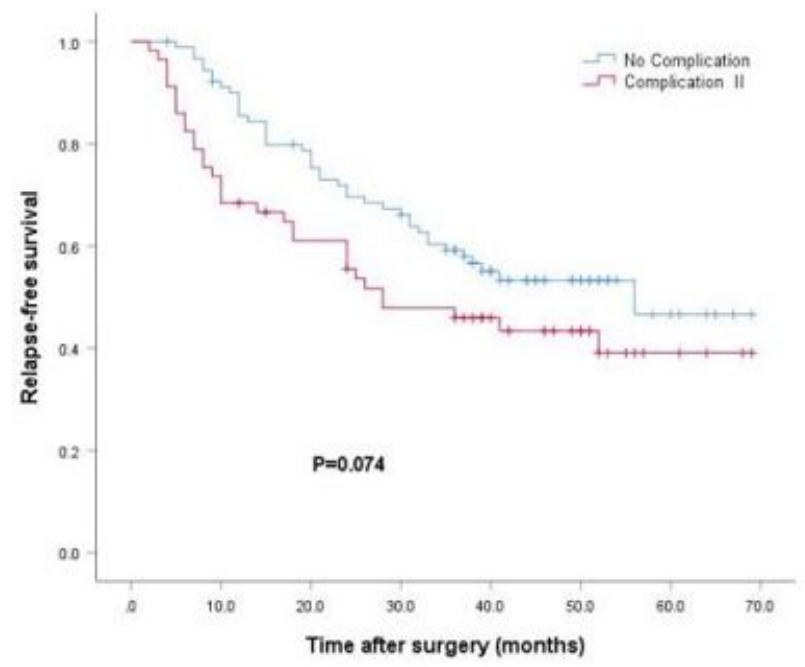

Figure 2

Comparison of matched NC group and grade II complications(B). 
$3 \mathrm{~A}$

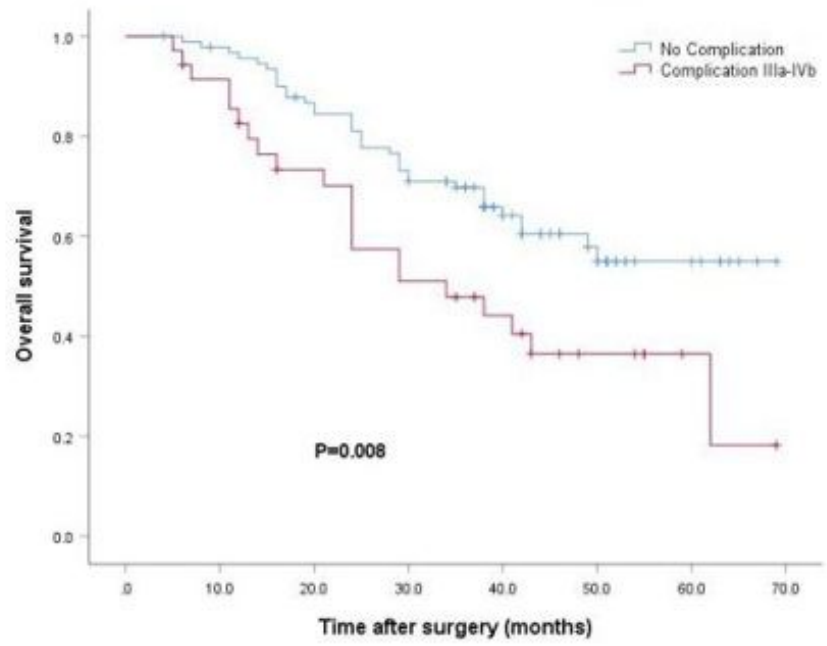

3B

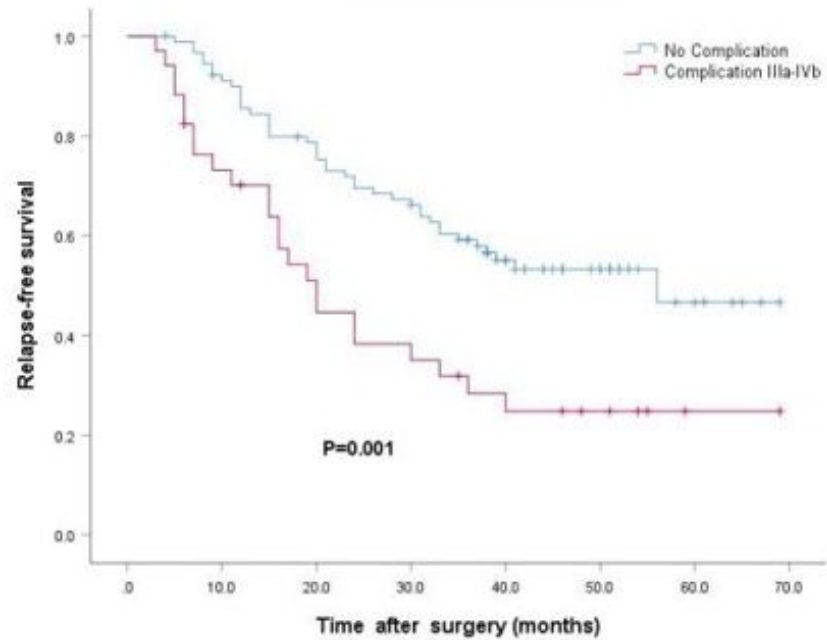

Figure 3

Comparisons of matched NC groups and severe complications(C).

$4 \mathrm{~A}$

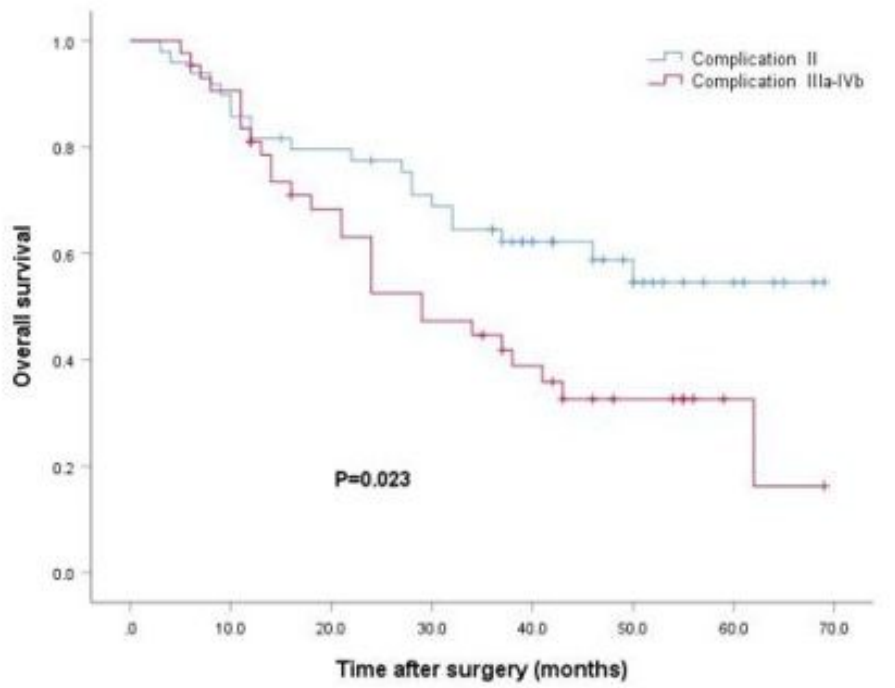

4B

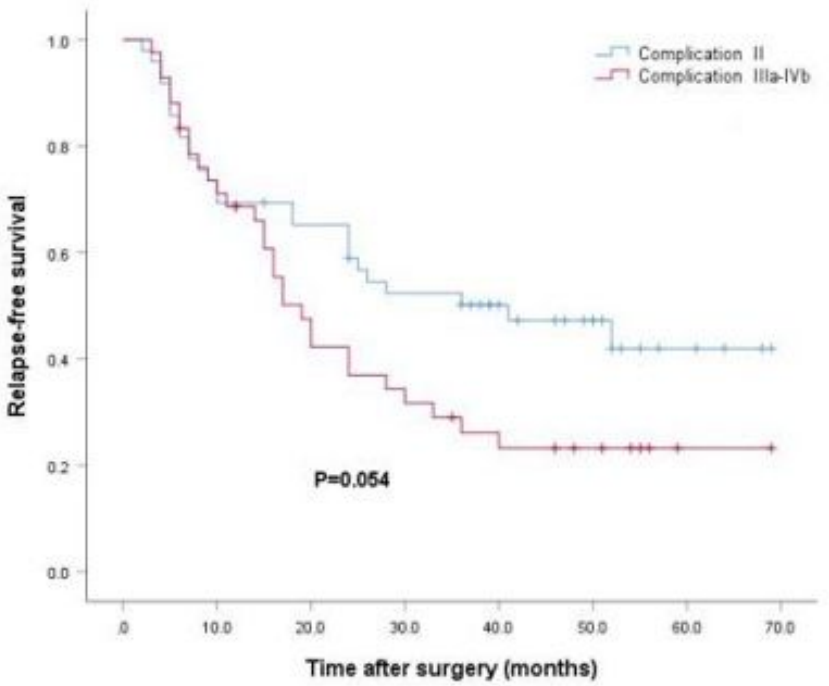

Figure 4

Comparison of grade II complications and severe complications(D). 